\title{
Wind Tunnel Investigation into the Resistance Analysis of Slender Body Catamaran
}

\author{
I K A P Utama ${ }^{1)^{*}}$, Sutiyo²), B Suwasono ${ }^{2)}$ \\ 1) Department of Naval Architecture, Faculty of Marine Technology, Institute of Technology Sepuluh Nopember, Surabaya 60111, Indonesia \\ ${ }^{2)}$ Department of Naval Architecture, Faculty of Engineering and Marine Science, Hang Tuah University, Surabaya 60111, Indonesia \\ *) Corresponding Author: kutama@na.its.ac.id
}

\section{Article Info}

Keywords:

Slender Body,

Catamaran,

Viscous,

Experiment

Article history:

Received: 02/05/20

Last revised: 11/06/20

Accepted: 17/06/20

Available online: 23/06/20

DOI:

https://doi.org/10.14710/kapal. v17i2.29867

\section{Abstract}

The Wind tunnel investigation of a slender body catamaran was conducted in order to determine its resistance characteristics, namely the effect of pressure and flow velocity changes for varied hull separation. The catamaran was tested in a wind tunnel belongs to Department of Mechanical Engineering, ITS, with hull separations of $S / L=0.2$ to 0.4 and variation in Reynolds numbers up to 4.46 $\mathrm{x} 10^{5}$. Pressure around the hull was measured using pressure tappings and the flow velocity behind the hull was also measured using a Pitôt-static tube. The experimental study shows that the pressure coefficient decreases when the hull separation declines and conversely, the flow velocity increases. The tests demonstrated a viscous interaction between the hulls, and form factors for the monohull and catamaran are derived. The demihull exhibited a form factor $(1+k)$ of 1.265 and in the catamaran mode, the measured form factor $(1+\beta k)$ was between 1.416 and 1.403 . The results are in agreement with other published data.

Copyright @ 2020 KAPAL : Jurnal Ilmu Pengetahuan dan Teknologi Kelautan. This is an open access article under the CC BY-SA license (https://creativecommons.org/licenses/by-sa/4.0/).

\section{Introduction}

The use of a wind tunnel for slender body catamaran investigations is described. This approach, in which the free surface is treated as a solid plane, allows the isolation of the viscous resistance but does not take account of any influences that surface waves may have on viscous resistance. The use of reflex models in a wind tunnel, therefore, provides an approximate means of directly measuring the total viscous resistance of the model [1], [2]. An implicit assumption for the reflex model is that the waterline is level.

Lackenby [3] carried out several tests on a catamaran model in a wind tunnel. The overall results of this work would indicate that the influences of surface waves on the viscous resistance are not large and that it should be acceptable to treat the viscous resistance in isolation, in this manner to investigate viscous components and form effects. The reflex model was a technique pioneered by experts such as Joubert et al. [4], where the resistance of the hull was measured in a wind tunnel. The investigation was extended to the BSRA trawler series, Joubert et al. [5]. Furthermore, Utama [6] conducted a detailed experimental investigation in a low-speed wind tunnel on a single ellipsoid (as a reflex model) and a pair of ellipsoids in close proximity representing a catamaran. Potential flow method has been carried out to determine the lift force single-dead rise hull and catamaran configurations in which hydrodynamic pressure are more pronounced between two catamaran hulls [7].

In the absence of waves, the pressure resistance is also the viscous pressure resistance, Molland et al. [8]. Then the total viscous resistance $R_{V}$ may be described as shown in Eq. 1:

$$
R_{V}=R_{F}+R_{V P}
$$

where $R_{F}$ is the frictional resistance arising from tangential shear forces on the hull and $R_{V P}$ is the viscous pressure resistance, arising from the normal pressure forces acting on the hull.In coefficient form is shown in Eq. 2:

$$
C_{V}=C_{F}+C_{V P}
$$

For a monohull (or demihull of a catamaran) is described in Eq. 3: 


$$
C_{V d e m i}=(1+k) C_{F}
$$

The viscous interference resistance of a catamaran can be expressed by Eq. 4, from Insel and Molland, [8].

$$
C_{V \text { catamaran }}=(1+\phi k) \sigma C_{F}
$$

The factor $\phi$ was introduced to take account of the pressure-field change around the demihulls and $\sigma$ takes account of the velocity augmentation between the hulls and would be calculated from an integration of the local frictional resistance over the wetted surface. $(1+k)$ is the form factor for the demihull in isolation [9]. For practical purposes, $\phi$ and $\sigma$ can be combined into a viscous interference factor $\beta$ where $(1+\phi k) \sigma=(1+\beta k)$, as shown in Eq. 5.

$$
C_{V \text { catamaran }}=(1+\beta k) C_{F}
$$

The friction resistance was determined using the ITTC- 57 extrapolation line, ITTC [10], is in Eq. 6.

$$
C_{F}=\frac{0.075}{(\log R e-2)^{2}}
$$

Pressure resistance may be estimated by integrating pressure coefficients over the hull, Utama [4], Molland et al. [5], and Armstrong [11], as written in Eq. 7.

$$
C_{V P}=\int C_{p} d s
$$

where $C_{P}$ is the pressure coefficient, $C_{V P}$ is viscous pressure resistance coefficient and $d s$ is the distance between two $C_{P}$.

The present experimental investigation was carried out in a wind tunnel on a symmetrical catamaran using a reflex model. The study objectives were to determine the viscous interferences due to pressure and flow velocity changes between the catamaran hulls and to derive viscous form factors in the demihull and catamaran modes.

\section{Methods}

The experiments were carried out in the low-speed open-circuit wind tunnel in the Mechanical Engineering Department at the Institut Teknologi Sepuluh Nopember (ITS) at Surabaya, Indonesia. The main particulars of the wind tunnel are as follows in Table 1. The overall layout of the wind tunnel is shown in Figure 1.

\begin{tabular}{ll} 
Table 1. Main Particulars of the Wind Tunnel \\
\hline Parameters & Dimension \\
\hline Test section & $660 \times 660 \mathrm{~mm}$ \\
Length of test section & $1800 \mathrm{~mm}$ \\
Maximum velocity & $20 \mathrm{~m} / \mathrm{s}$ \\
\hline
\end{tabular}

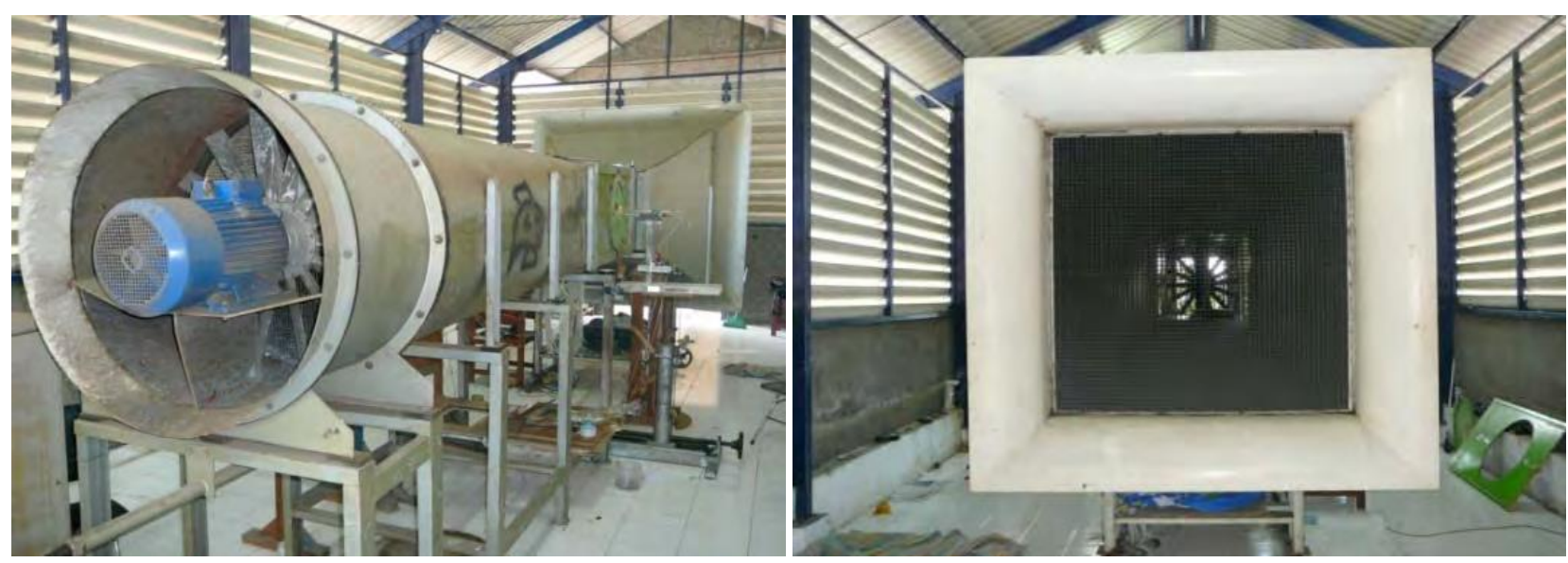

Figure 1. Open Circuit Wind Tunnel

The catamaran model with two identical hulls was constructed from wooden materials with identical dimensions. The demihull had an overall length of $457 \mathrm{~mm}$, a width of $475 \mathrm{~mm}$, and a surface area of $0.0284 \mathrm{~m}^{2}$. One of the demihulls was fitted with 60 pressure tappings in order to measure the pressure distribution over its surface. See Figure 2. 


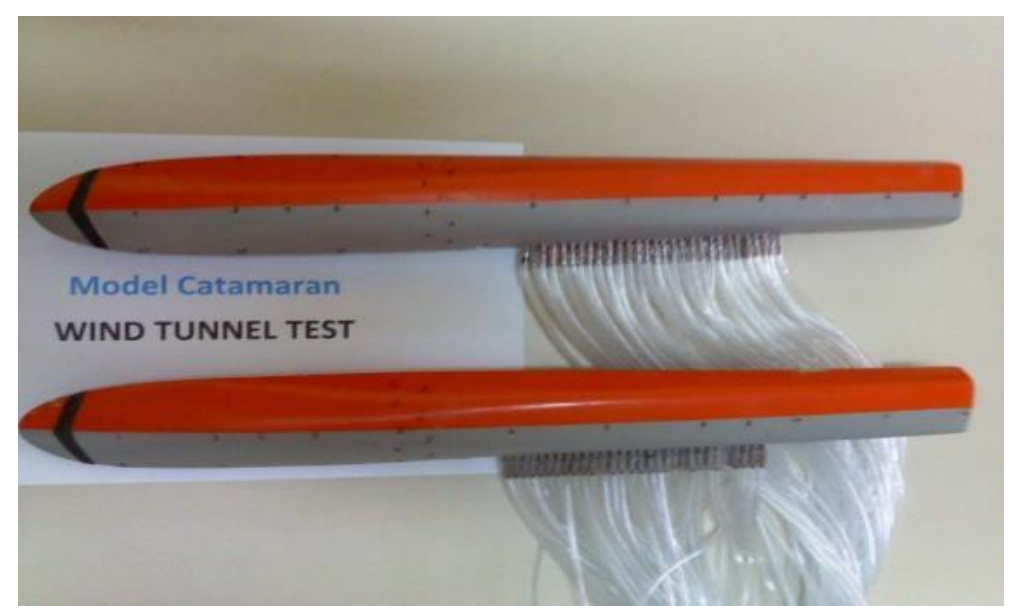

(a)

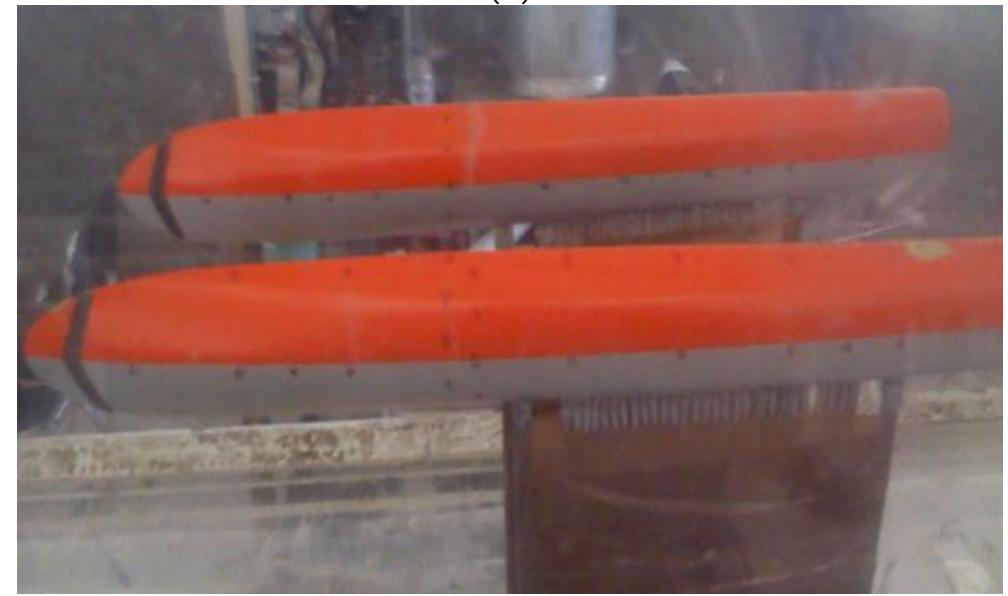

(b)

Figure 2. Reflex Model of Catamaran in the Wind Tunnel. (a) Geomety Model Experiment, (b) Model Mounting

The circumferential and longitudinal positions of the pressure tappings are given in Figure 3. Leading-edge roughness (a turbulence strip) was applied to each demihull. The turbulence stimulation comprised sand grain strips of $0.2 \mathrm{~mm}$ diameter and $4 \mathrm{~mm}$ width. The strips were situated about 5 percent aft of the leading edge of each demihull.

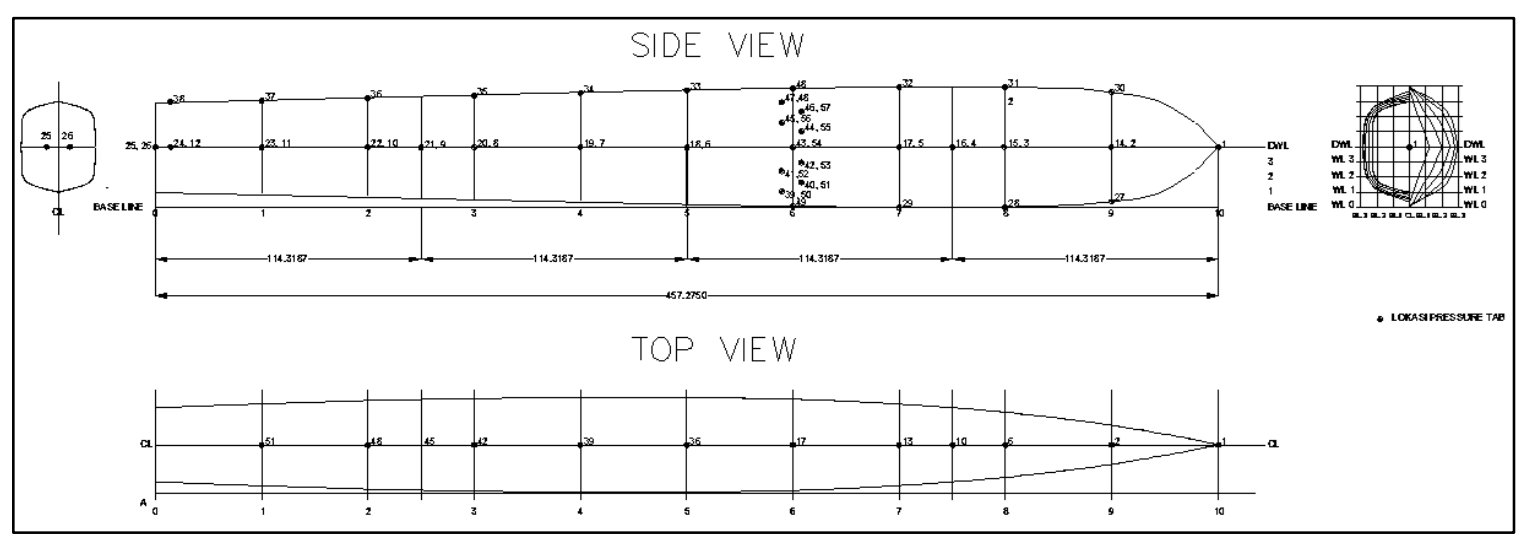

Figure 3. Circumferential and Longitudinal Location of Pressure Tappings

The static pressure is a constant value that is determined by the flow outside the boundary layer. The velocity varies from its free stream value to zero at the wall. The total pressure also varies from free stream to the wall in the same way that the velocity varies. In order to measure the total pressure on a rake, long thin tubes connect the rake tubes to a pressure transducer located outside the wind tunnel [12].

Any blockage effects were minimized by keeping the model cross-sectional area small when compared with the tunnel cross-sectional area $(<0.7 \%)$, and the interference effects of the support structure were minimized by the use of a minimum of support and by shaping the support structure for minimum drag [7], [8]. The demihulls could be adjusted laterally to alter the separation between the two hulls. The location of the Pitot-static tube is shown schematically in Figure 4 . The models were tested at separation/length ratios $(S / L)$ of $0.2,0.3$, and 0.4 . 


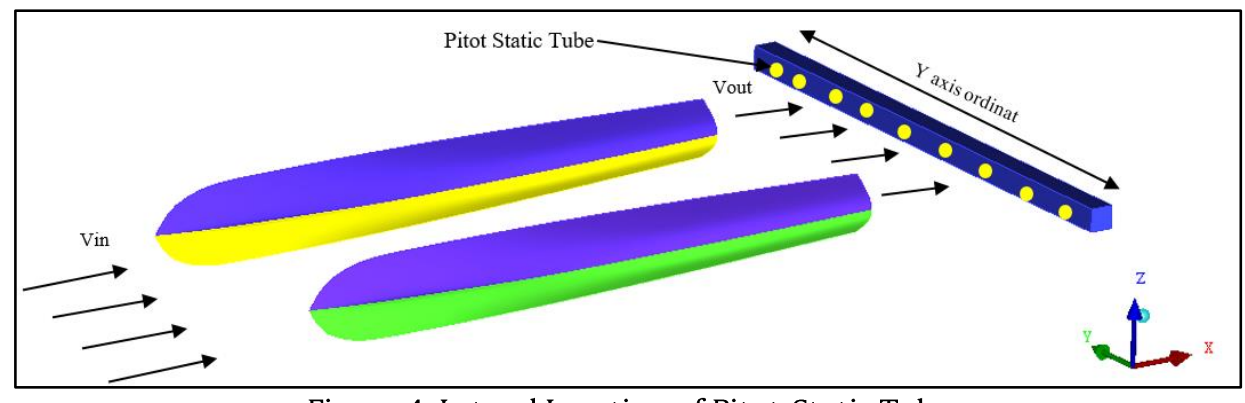

Figure 4. Lateral Location of Pitot-Static Tube

Pressure on the hull model's surface is measured by several pressure taps with a position on the water laden (draft) along the hull to determine the pressure distribution around (between) the hull. Then the flow velocity is measured with a pitot-static tube connected to the manometer, where the pitot-static tube is placed behind the two hulls with a shift in the lateral direction of the Y-axis. The current research was carried out at wind speeds of 10,12, 14 and $15.4 \mathrm{~m} / \mathrm{s}$, giving Reynolds numbers (based on model length) of up to $4.46 \times 10^{5}$. Wind tunnel corrections were applied according to Glauert's formula [13], [14]. The only significant correction was that due to solid-body blockage, but this amounted to a correction to the drag of up to only $0.2 \%$ for the catamaran configuration [15].

\section{Results and Discussion}

The technique of testing in a wind tunnel allows the pressure and flow velocity on the demihull and catamaran models to be measured directly. The pressure and flow velocity changes due to the change of catamaran hull separation were determined. The frictional drag was determined using the ITTC' 57 correlation line, Eq. 6. The viscous pressure drag is caused by the development of the boundary layer along the model owing to the viscosity of the fluid, and the consequent changing of pressure which increases in magnitude as the boundary layer develops, which causes a drop in the pressure recovery in the after part of the hull, Armstrong [11].

The pressures were integrated over the hull surface to determine the viscous pressure drag. The total viscous drag at given wind speed could thus be determined, comprising the frictional drag or shear force $\left(R_{F}\right)$ and the viscous pressure or normal forces $\left(\mathrm{R}_{\mathrm{VP}}\right)$, as shown in Eq. 1. The effects on viscous drag of separation of the hulls in a catamaran configuration could also be found by using two hulls. Flow velocity was measured downstream of the model at a distance of about $30 \%$ of the ship's length. The probe was moved laterally across the wake and covered more than the width of the hulls. In this case, there are 25 measurement points for the monohull and 60 points for the catamaran configuration.

\subsection{Pressure Results}

The pressure variation around the hull at various demihull spacings is illustrated in Figures 5, 6, and 7. In the case of the catamaran, the pressure and flow velocities that occur on the outer and inner side along the hull show a difference. The interference factor ratio (inner/outer) for flow velocity $(\sigma)$ shows that the larger the hull separation, the smaller the velocity difference and vice versa for the pressure ratio ø, as shown in Figures 5, 6 to 7 and Table 2.

Table 2. Interference of Flow Velocity $(\sigma)$ and Pressure $(\varnothing)$ from Wind Tunnel Data (Inner/Outer)

\begin{tabular}{lllllll}
\hline Reynolds Number & \multicolumn{3}{l}{ Flow velocity ratio $(\sigma)$} & \multicolumn{3}{l}{ Pressure ratio $(\boldsymbol{\emptyset})$} \\
\cline { 2 - 7 } & $\mathrm{S} / \mathrm{L}=\mathbf{0 . 2}$ & $\mathrm{S} / \mathrm{L}=\mathbf{0 . 3}$ & $\mathrm{S} / \mathrm{L}=\mathbf{0 . 4}$ & $\mathrm{S} / \mathrm{L}=\mathbf{0 . 2}$ & $\mathrm{S} / \mathrm{L}=\mathbf{0 . 3}$ & $\mathrm{S} / \mathrm{L}=\mathbf{0 . 4}$ \\
\hline $2.89 \times 10^{5}$ & 1.0899 & 1.0571 & 1.0427 & 0.9939 & 0.9961 & 0.9979 \\
$3.47 \times 10^{5}$ & 1.0761 & 1.0512 & 1.0399 & 0.9923 & 0.9954 & 0.9965 \\
$4.05 \times 10^{5}$ & 1.0511 & 1.0369 & 1.0257 & 0.9930 & 0.9964 & 0.9979 \\
$4.46 \times 10^{5}$ & 1.0324 & 1.0228 & 1.0159 & 0.9929 & 0.9959 & 0.9967 \\
\hline
\end{tabular}

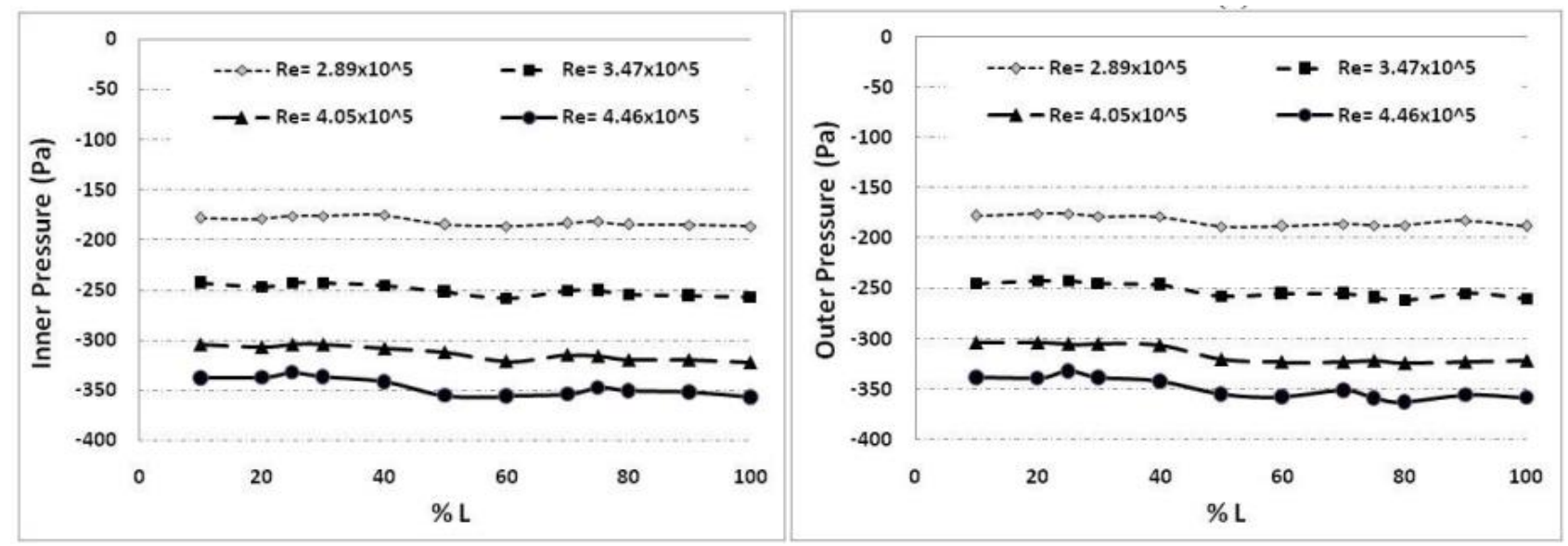

Figure 5. Pressure Coefficient for Catamaran, $\mathrm{S} / \mathrm{L}=0.2$ 

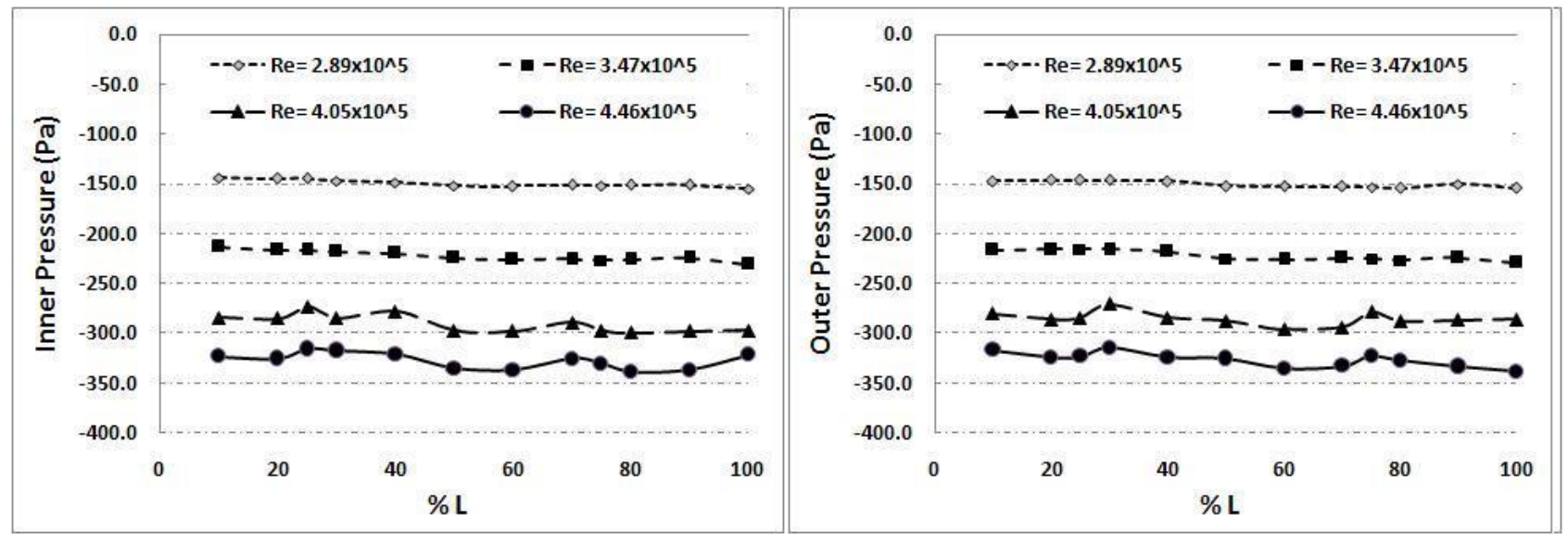

Figure 6. Pressure Coefficient for Catamaran, $\mathrm{S} / \mathrm{L}=0.3$
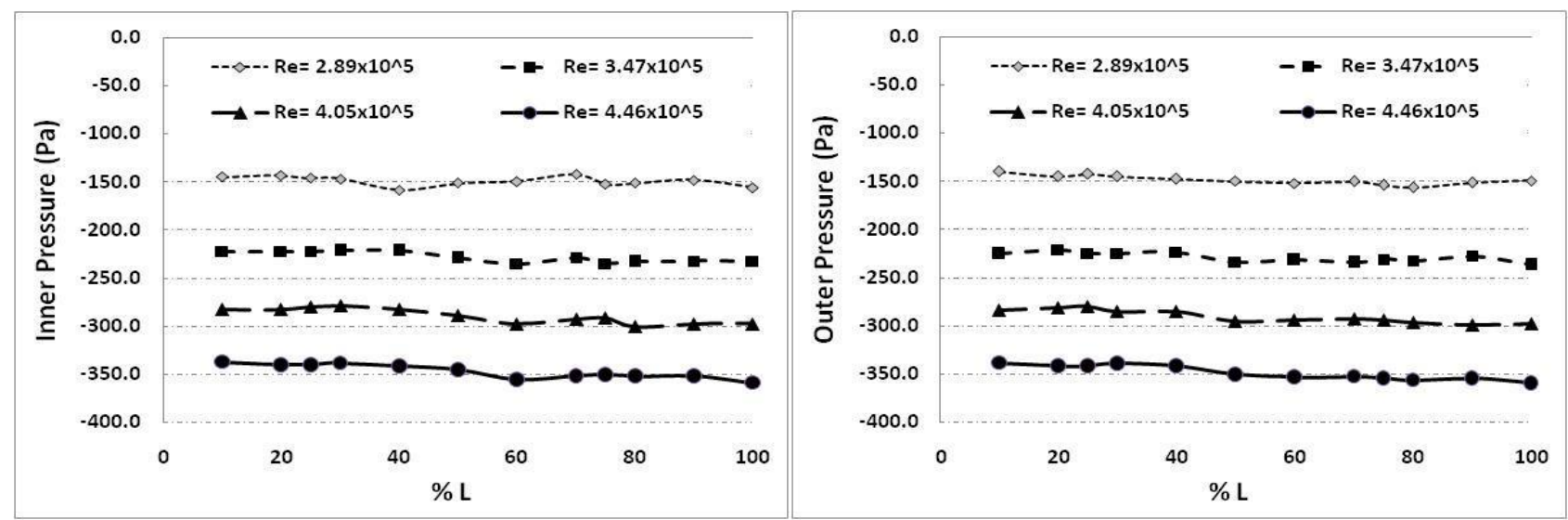

Figure 7. Pressure Coefficient for Catamaran, $\mathrm{S} / \mathrm{L}=0.4$

\subsection{Flow Velocity Results}

Plots of flow velocities along lateral locations at various hull spacings are given in Figures 8, 9, and 10. When approaching the bow of the model, airflow velocity will experience a slowdown and the flow rate will increase at the centre between the hulls. The smaller the distance between the hulls, the greater the flow velocity occurred. Further aft, at the stern of the model, the flow velocity re-experiences a slowing down due to dilation of the media stream, and in this condition, an increase in pressure. Figures 8, 9, 10 clearly show the wake deficits behind each of the catamaran hulls. The slowing down effect behind each hull is seen to be relatively insensitive to hull separation.

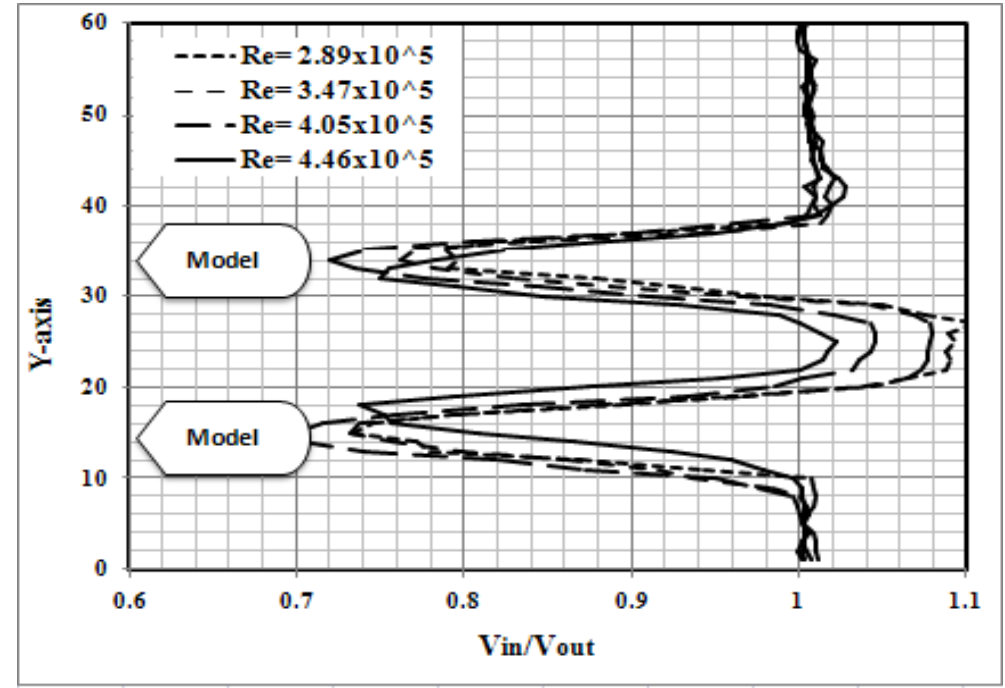

Figure 8. Horizontal Velocity Distribution, $S / L=0.2$ 


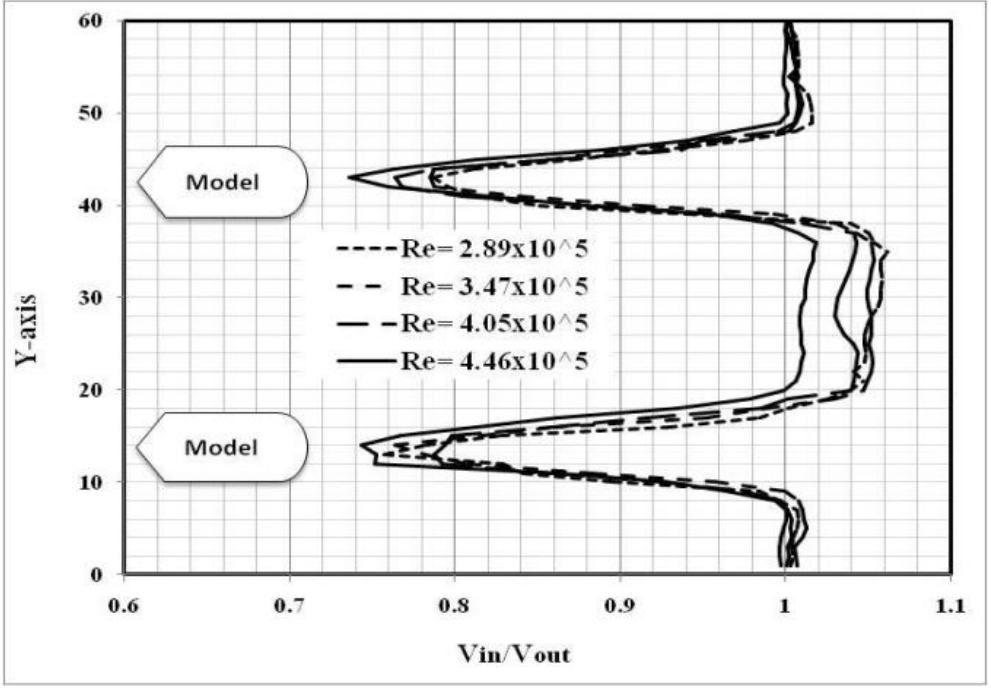

Figure 9. Horizontal Velocity Distribution, $S / L=0.3$

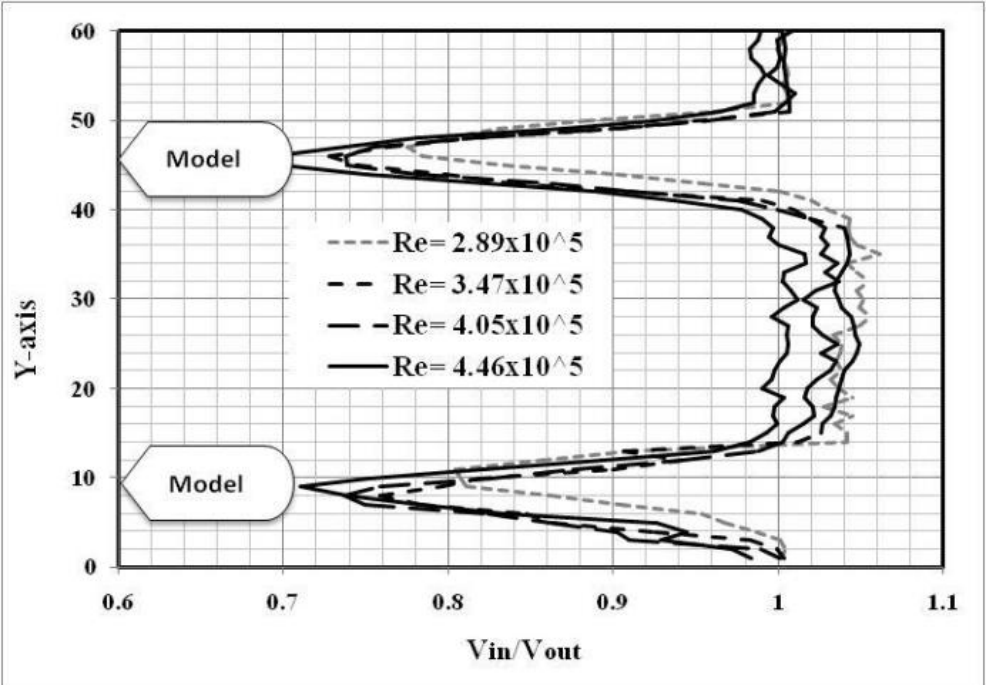

Figure 10. Horizontal Velocity Distribution, $S / L=0.4$

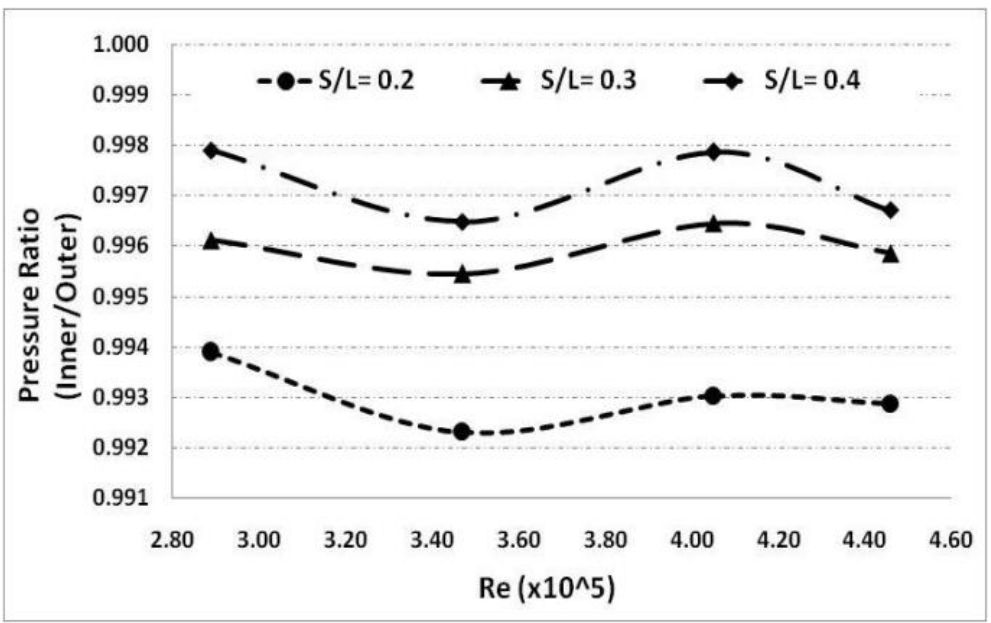

Figure 11. Ratio of Pressure Changes Based on Re and $S / L$ 


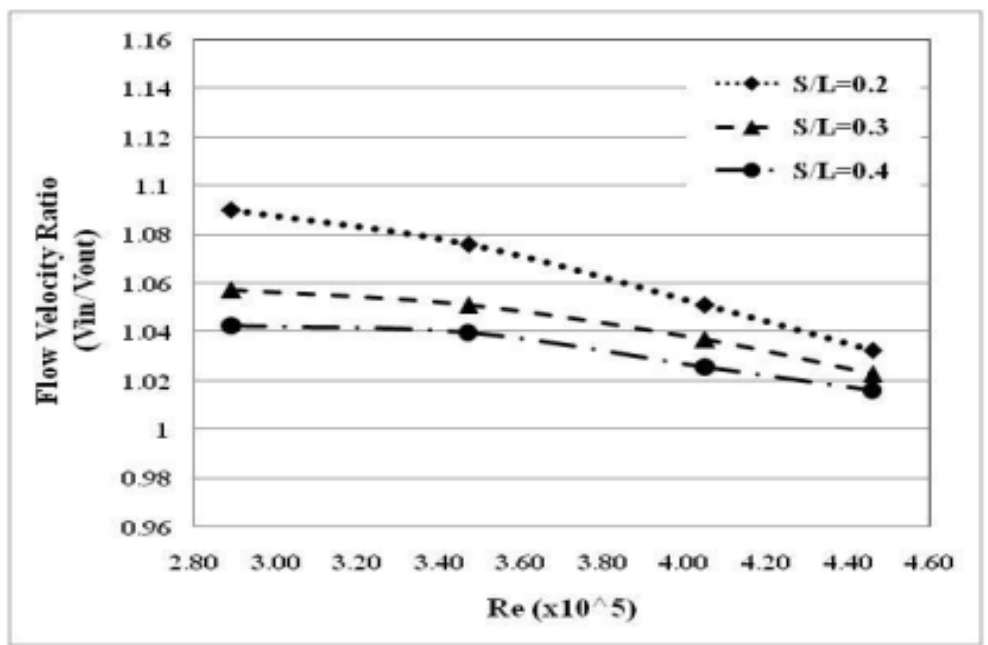

(a)

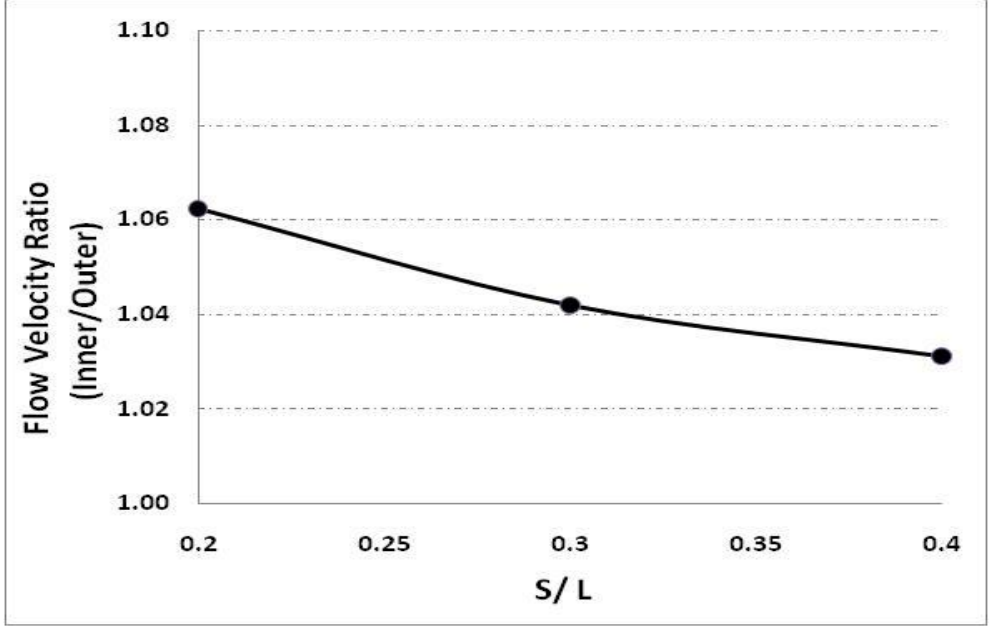

(b)

Figure 12. Ratio of Flow Velocity Changes Based on $\operatorname{Re}(\mathrm{a})$ and $S / L(\mathrm{~b})$

Table 3. Viscous Resistance Values

\begin{tabular}{lllllll}
\hline $\begin{array}{l}\text { Hull } \\
\text { Cofiguration }\end{array}$ & $\begin{array}{l}\text { Reynold } \\
\text { Number }\end{array}$ & $\int_{0}^{L}$ Cpds & Cvp $^{\prime}$ & CF & $\begin{array}{l}\text { Cv }=\text { Cvp' }+ \text { CF } \\
\text { (Corrected) }\end{array}$ & Cv/CF \\
\hline Demi & $2.89 \times 10^{5}$ & 0.0624 & 0.0017 & 0.0063 & 0.0080 & 1.2725 \\
& $3.47 \times 10^{5}$ & 0.0589 & 0.0016 & 0.0060 & 0.0076 & 1.2696 \\
& $4.05 \times 10^{5}$ & 0.0564 & 0.0015 & 0.0058 & 0.0073 & 1.2678 \\
$\mathrm{~S} / \mathrm{L}=0.2$ & $4.46 \times 10^{5}$ & 0.0548 & 0.0015 & 0.0056 & 0.0071 & 1.2660 \\
& $2.89 \times 10^{5}$ & 0.0962 & 0.0026 & 0.0063 & 0.0089 & 1.4205 \\
& $3.47 \times 10^{5}$ & 0.0923 & 0.0025 & 0.0060 & 0.0085 & 1.4219 \\
& $4.05 \times 10^{5}$ & 0.0880 & 0.0024 & 0.0058 & 0.0082 & 1.4180 \\
$\mathrm{~S} / \mathrm{L}=0.3$ & $4.46 \times 10^{5}$ & 0.0862 & 0.0024 & 0.0056 & 0.0080 & 1.4188 \\
& $2.89 \times 10^{5}$ & 0.0937 & 0.0026 & 0.0064 & 0.0089 & 1.4029 \\
& $3.47 \times 10^{5}$ & 0.0914 & 0.0025 & 0.0060 & 0.0085 & 1.4181 \\
& $4.05 \times 10^{5}$ & 0.0868 & 0.0024 & 0.0058 & 0.0081 & 1.4119 \\
$\mathrm{~S} / \mathrm{L}=0.4$ & $4.46 \times 10^{5}$ & 0.0841 & 0.0023 & 0.0056 & 0.0079 & 1.4083 \\
& $2.89 \times 10^{5}$ & 0.0943 & 0.0026 & 0.0063 & 0.0088 & 1.4119 \\
& $3.47 \times 10^{5}$ & 0.0897 & 0.0025 & 0.0060 & 0.0084 & 1.4100 \\
& $4.05 \times 10^{5}$ & 0.0863 & 0.0024 & 0.0058 & 0.0081 & 1.4095 \\
& $4.46 \times 10^{5}$ & 0.0836 & 0.0023 & 0.0056 & 0.0079 & 1.4058 \\
\hline
\end{tabular}

Figure 11 shows that the pressure ratio (inner pressure/outer pressure) is relatively insensitive to Re but shows an upsurge with an increase in hull separation $S / L$. Figure 12 indicates that there is a decrease in the flow velocity ratio with increase in $R e$, and a decrease with increase in $S / L$. Since $C_{P}(E q .7)$ is based on a maximum cross-sectional area, CSA (while $\mathrm{C}_{\mathrm{VP}}$ is based on the wetted surface area, WSA), the results must be multiplied by a factor (CSA/WSA). The corrected $\mathrm{C}_{\mathrm{VP}}$ is then:

$$
C_{V P^{\prime}}=\frac{C S A}{W S A} \times C_{P}
$$


where, $C S A=0.0007778 \mathrm{~m}^{2}$ and WSA $=0.028444 \mathrm{~m}^{2}$. The results obtained for viscous pressure resistance and total viscous resistance, together with skin friction resistance, are shown in Table 3.

Figures 13 and 14 show the effects of $R e$ and $S / L$ on total viscous resistance $C_{V}$ and viscous pressure resistance $C_{V p}$. There is a distinct decrease in resistance with an increase in $R e$, with the effect decreasing at the highest Re. There is a change in $C_{V}$ with decreasing hull separation ratio $S / L$, Figure 13, and it is clear from Table 3 and Figure 14 that it is almost entirely because of variations in the value of $\mathrm{C}_{\mathrm{VP}}$. This phenomenon is also described by Armstrong [11] in his experimental work on the NPL catamaran model.

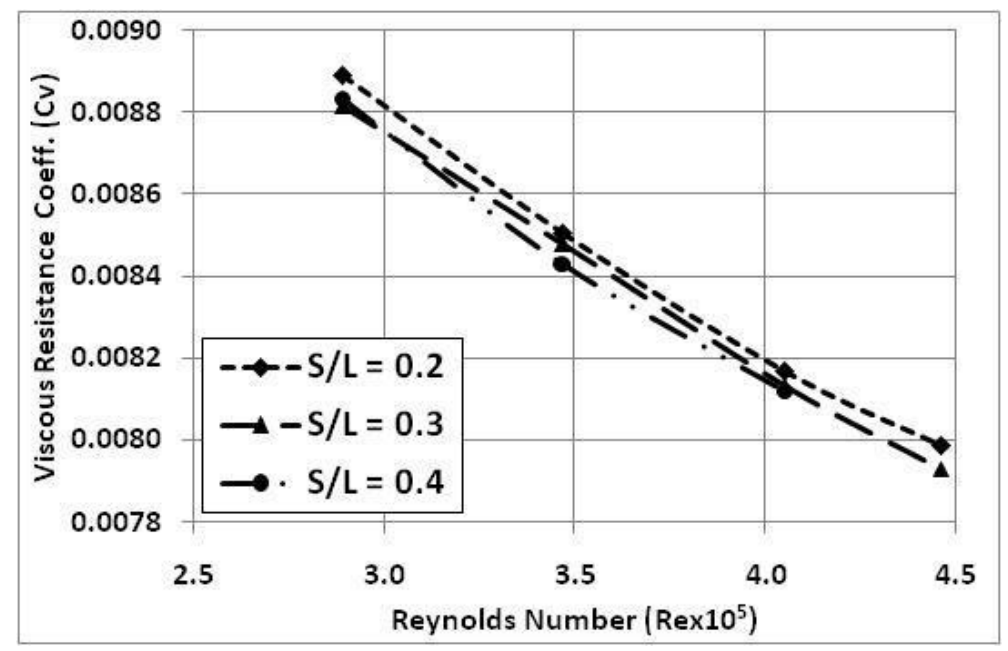

Figure 13. Effect of Hull Separation on Total Viscous Resistance

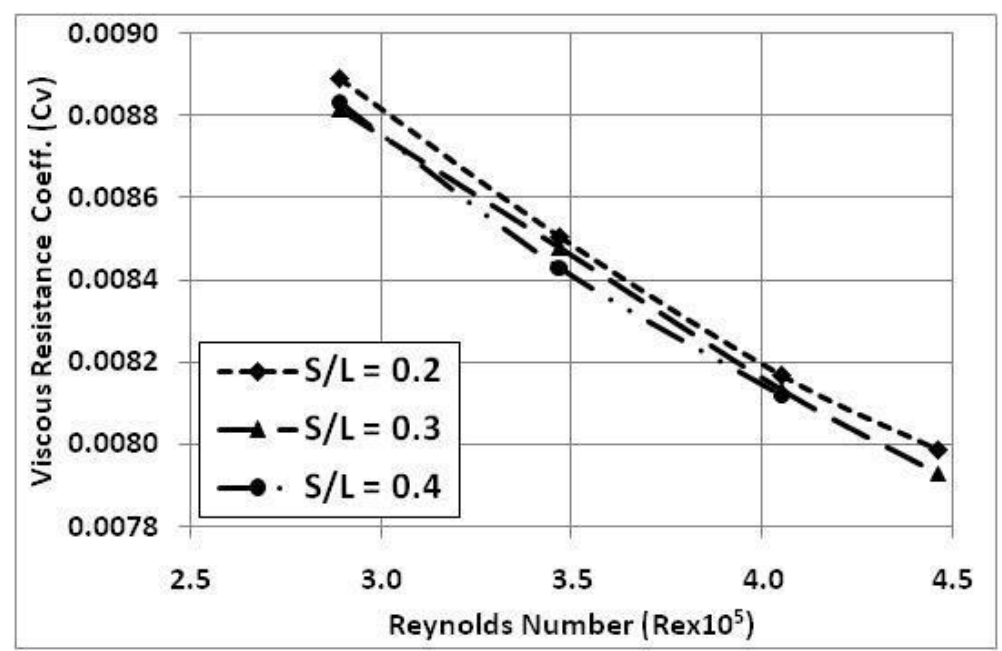

Figure 14. Effect of Hull Separation On Viscous Pressure Resistance

Table 4 shows the test results for the viscous form factor for demihull (monohull) and catamaran, using the highest Re value $\left(4.46 \times 10^{5}\right)$. The form factor for the demihull $(1+k)$ and catamaran $(1+\beta k)$ are derived from $\frac{C_{V}}{C_{F}}$ using Eq. 3 and Eq. 5 .

\begin{tabular}{llll}
\multicolumn{3}{l}{ Table 4. Experimental Viscous Form Factor Values } \\
\hline $\begin{array}{l}\text { Demihull } \\
(\mathbf{1}+\mathbf{k})\end{array}$ & \multicolumn{2}{l}{ Catamaran $(\mathbf{1}+\boldsymbol{\beta} \mathrm{k})$} \\
\cline { 2 - 4 } & $\mathrm{S} / \mathrm{L}=\mathbf{0 . 2}$ & $\mathrm{S} / \mathrm{L}=\mathbf{0 . 3}$ & $\mathrm{S} / \mathrm{L}=\mathbf{0 . 4}$ \\
\hline 1.265 & 1.416 & 1.405 & 1.403 \\
\hline
\end{tabular}

The present study with the demihull and catamaran demonstrated clearly a form effect on the demihull and a viscous interaction between the hulls, Table 3. The demihull exhibited a form factor $(1+k)$ of 1.265 and in the catamaran mode, the measured form factor $(1+\beta k)$ was between 1.416 and 1.403 . The results in Table 3 indicate a viscous interaction of the order of 10-12 per cent of the demihull viscous drag; also, there is little effective change in $(1+\beta k)$ with a change in hull separation $S / L$, a characteristic that had been observed elsewhere such as Utama [6], [13] and Luhulima [16]. It should be kept in mind that the values of $(1+\beta k)$ vary with model shape, size and $R e$, Armstrong [11].

\section{Conclusion}

The effects of various hull separations for a catamaran were analysed in a wind tunnel. From the wind tunnel test results, the following conclusion can be drawn: a) The experimental techniques employed have provided a better understanding of the physical flow processes when two bodies, such as the hulls of a catamaran, are in close proximity. b)The 
result test of demihull and catamaran with S/L variations shows increasing total viscous resistance about 12-14 per cent. c) The base pressure coefficient showed a decrease when the hull separation was small while the flow velocity showed an increase i.e. with an indication of $(1+\beta k)$ changes from 1.416 to 1.403 . $d)$ The results show that the viscous resistance is affected by the change of hull separation $(\mathrm{S} / \mathrm{L})$, although the effects are relatively small. The results indicate that the smaller the separation $(\mathrm{S} / \mathrm{L})$, the higher the resistance. It is apparent that the quality of the overall ship resistance estimate can rely heavily on the magnitude of the viscous resistance component and hence the value of the form factor.

\section{Acknowledgements}

The first authors wished to thank the Directorate of Research and Community Engagement (DPRM) of the Institut Teknologi Sepuluh Nopember (ITS), which funded part of the work under a research scheme called "Postgraduate Research Grant" with contract number: 920/PKS/ITS/2020.

\section{References}

[1] A. Jamaluddin, I. Utama, B. Widodo, and A. Molland, "Experimental and numerical study of the resistance component interactions of catamarans," Proceedings of the Institution of Mechanical Engineers, Part M: Journal of Engineering for the Maritime Environment, vol. 227, no. 1, pp. 51-60, Feb. 2013, doi: 10.1177/1475090212451694.

[2] Sutiyo, E. Yuliora, and I. K. A. P. Utama, "Numerical Investigation Into The Pressure Distribution And Form Factor Effect Of Slenderbody Catamaran," in Proceeding of the International Conference on Ship and Technology (ICSOT) 2019, Developments Marine Design Architecture, 2019, no. November, pp. 25-26.

[3] H. Lackenby, "On the Systematic Geometrical Variation of Ship Forms," Transactions of the TINA, 1950.

[4] P. N. Joubert and N. Matheson, "Wind tunnel tests of two Lucy Ashton reflex geosims," Journal of Ship Research, vol. 14, no. 4, 1970.

[5] P. N. Joubert and P. H. Hoffman, "AN EXPERIMENTAL STUDY OF THE VISCOUS RESISTANCE OF A 0.564-C SUB B FORM," Journal of Ship Research, vol. 23, no. 2, 1979.

[6] A. F. Molland and I. K. A. P. Utama, "Experimental and numerical investigations into the drag characteristics of a pair of ellipsoids in close proximity," Proceedings of the Institution of Mechanical engineers, Part M: Journal of Engineering for the Maritime Environment, vol. 216, no. 2, pp. 107-115, Dec. 2002, doi: 10.1243/147509002762224324.

[7] G. S. Bari and K. I. Matveev, "Hydrodynamics of single-deadrise hulls and their catamaran configurations," International Journal of Naval Architecture and Ocean Engineering, vol. 9, no. 3, 2017, doi: 10.1016/j.ijnaoe.2016.11.001.

[8] M. Insel and A. F. Molland, "An Investigation Into Resistance Components of High Speed Displacement Catamarans," RINA, vol. 134, 1992.

[9] A. Farkas, N. Degiuli, and I. Martić, "Numerical investigation into the interaction of resistance components for a series 60 catamaran," Ocean Engineering, vol. 146, pp. 151-169, 2017, doi: 10.1016/j.oceaneng.2017.09.043.

[10] ITTC, "ITTC - Recommended Procedures Testing and Extrapolation Methods Resistance Test," Int. Towing Tank Conf., 2002.

[11] T. Armstrong, "The Effect Of Demihull Separation On The Frictional Resistance Of Catamarans," in FAST 2003 The 7th International Conference on Fast Sea Transportation, 2003.

[12] C. L. Ford and P. M. Winroth, "On the scaling and topology of confined bluff-body flows," Journal of Fluid Mechanics, vol. 876, pp. 1018-1040, 2019, doi: 10.1017/jfm.2019.583.

[13] I. K. A. P. Utama, "Investigation of the viscous resistance components of catamaran forms," University Of Southampton (United Kingdom), 1999.

[14] H. Glauert, "Wind Tunnel Interference on Wings, Bodies and Airscrews," Aeronaut. Res. Comm. Reports Memo. No. 1566, no. 1566, 1933.

[15] ESDU, 80024, "Blockage Corrections for Bluff Bodies in Confined Flows," 1980.

[16] R. B. Luhulima, I. K. A. P. Utama, and A. Sulisetyono, "Experimental Investigation into the Resistance Components of Displacement Trimaran at Various Lateral Spacings," International Journal of Engineering Research \& Science, vol. 2 , no. 7, pp. 2395-6992, 2016. 